Concept Paper

\title{
To Be or Not to Be: Social Justice in Networked Learning
}

\author{
Murat Öztok \\ Department of Educational Research, Lancaster University, Lancaster LA1 4YD, UK; m.oztok@lancaster.ac.uk \\ Received: 2 September 2019; Accepted: 22 October 2019; Published: 23 October 2019 \\ check for \\ updates
}

\begin{abstract}
The potential for more egalitarian or democratic forms of engagements among people is accepted to be somehow actualised naturally within collaborative or cooperative forms of learning. There is an urgent need for a theoretical framework that does not limit social justice with access or participation, but focuses on the otherwise hidden ways in which group work can yield suboptimal outcomes. This article aims to expand the current understandings of social justice in networked learning practices by challenging the ways in which online subjectivities are conceptualised in communal settings. It is argued that the mediated experience in online spaces should be conceptualised in tandem with one's social presence and social absence if education is to be studied more rigorously and if claims of justice are to be made in networked learning.
\end{abstract}

Keywords: social justice; social presence; social absence; discourses; community; group work

\section{Introduction}

The answers for questions concerning social justice in collaborative or cooperative forms of education can be defined as largely untested and often self-referential. The core to these claims is the rhetoric that the networked nature of such practices can provide equal opportunities for all individuals to freely and openly share their ideas and participate in group activities (see, for example, [1,2]). The research reporting on empirical data, such as studies illustrating the variety of identities among participants (e.g., [3]) or comparing the number of contributions across different cohorts of students (e.g., [4]), can provide only tangential support for these idealistic propositions. This potential for more egalitarian or democratic forms of engagements among people is accepted to be somehow actualised naturally within collaborative or cooperative forms of learning. This assumption is problematic because researchers in the field of education continue employing frameworks that cannot reflect the nuanced ways in which complexly interwoven forms of identifications (such as class, ethnicity, sexual orientation, and gender) operate to produce differentiated experiences across cohorts of students. There is an urgent need for a theoretical framework that does not limit equity with access or participation but focuses on the otherwise hidden ways in which group work can yield suboptimal outcomes. If networked learning is becoming more diverse and widened [5], research should critically examine the extent to which these claims can be substantiated in practice.

This article aims to expand the current understandings of social justice in networked learning practices by challenging the ways in which being is conceptualised in communal settings. In specific, it provides a theoretical lens for going beyond a wide-spread speculation that networked learning practices inherently provide equal opportunities to participate, a speculation that has long hindered the development of critical frameworks and approaches in the theory of networked learning. By problematising the engagements, relations and connections among people in networked spaces, this article aims to generate a new research agenda in networked learning concerning social justice. 
This, however, requires clarification of what networked learning is and how social justice is conceptualised before proceeding further with the conceptual analysis. Networked learning is an umbrella term for pedagogical approaches or applications where technology is utilised to connect learners, tutor(s), and resources to form a learning network [6]. In networked learning, knowledge is distributed through and mediated by the participants of a community [7]. Accordingly, learning is not an individual pursuit but a collective effort. It is a matter of engagement with others in a community. As a value-laden term, the concept of justice is a contextual decision about what is right or fair [8]. At this point, it should be asserted that the difference between justice and equality (since, as it is argued above, research tends to employ the concept of equality when making claims on social justice). Equality refers to an arbitrary point of equilibrium: It is quantitative sameness or evenness. Justice, on the other hand, is a qualitative judgement on fairness. To determine what is socially just, therefore, is not limited with concerns whether there is an actual or perceived equality in a given situation, but includes judgements on whether the given situation is fair or not.

It is argued that if social justice is a concept that requires qualitative judgements about a given situation rather than quantified measurements [9], regressing or accumulating individuals and their experiences into measurable categories cannot account for the uniqueness of each individual neither can it explain how cultural differences play a role in networked learning activities. To understand how subjectivities are constructed, managed and negotiated within a community is needed.

In what follows, one such framework is discussed in online education with respect to the principles of networked learning. First, the focus is needed on online selves to better understand the relation of identification to learning in networked spaces. Then, the current conceptualisations of being in online spaces are explored and the need for the concept of social absence is argued. Lastly, a discussion is made that the mediated experience in online spaces should be conceptualised in tandem with one's social presence and social absence if online education is to be studied more rigorously and if claims of equity and justice are to be made in networked learning.

\section{The Relationship Between Being and Learning in Networked Spaces}

The networked learning is built on the principle that learning is simultaneously an individual and cultural process [10], that is, a process of discovering and articulating oneself in relation to others [11]. In other words, it is the material, symbolic and intellectual reconstruction of self through mediation between self and others. To determine what mediates between the self and the others-between the personal and social—is referred to as subjectivity. The process of education, therefore, is the process of reshaping the individuals' subjectivity [12]. In the field of online education, subjectivity is studied through the concept of social presence. It is regarded as the degree to which individuals represent themselves and perceive others in digitally-mediated spaces [13]. The concept of social presence has long been employed to study human experience in online spaces and has been central for attempts to examine how individuals engage with one another by interacting with and reacting to others [14].

Social presence is constructed dialogically. It is grounded in how individuals perform their state of being while they socialise within a particular context [7]. As a dialogic construction, it operates "on the boundary between two consciousness, two subjects" [15] (p 106). It is through this mediation between the self and others that social presence not only conveys meanings about individuals, but also forms the social fabric that determines what is acceptable in a given context [16]. Consequently, the construction of social presence is not an improvisation without a script but is derived from sociocultural norms and thus is constrained by norms, values, beliefs and perspectives [17]. By accepting, rejecting, redefining or simply reproducing subjectivities in online spaces, individuals choose their identifications from their repertoire of practices and enact their subjectivities in online spaces [7].

However, while the documented nature of social presence may hold some truth, such perspectives solely focus on what is visible but ignore the implicit ways in which online selves are socially constructed. Precisely because social presence is derived from sociocultural norms [18], conceptualising social presence with respect to both what is visible and invisible can help achieve a better understanding of 
learning in collaborative or cooperative activities in online spaces. The importance of this approach is rooted in one of the fundamental theories of networked learning: Knowledge is not an isolated entity, but socially constructed within a learning community [19].

It is argued that a comprehensive understanding of learning in online spaces should go beyond the apparent self-representations and further include the categories of identification that individuals consciously filter-out when they create their online existence. That is, the process of creating an online self is not only articulated by what is represented but also defined by what is filtered-out in that particular representation. I shall term these filtered-out identifications, social absence.

It is important to note that the concept of social absence is distinguished from the concept of anonymity. Anonymity has long been employed to explore and explain the impersonal nature of online spaces. It has been the scapegoat for problems associated with teaching and learning in group work [20]. According to the Oxford Online Dictionary, anonymity connotes a lack of ownership or impersonality while absence refers to not-being in a particular space/time configuration. In this sense, social absence is not an attempt to refashion anonymity with a new outlook. Rather, it is a theoretical lens that goes beyond it to provide a more rigorous and comprehensive explanation for the phenomenon of being online. For example, the concept of social absence can explain why individuals may enact in conformity with others and reconfigure their identity to prevent being excluded or isolated. It is argued that the dynamic interplay between social presence and social absence can provide the means to understand the otherwise hidden effects of Discourses on the construction of self in online spaces. In particular, the degree of social absence can explain the ways discourses operate to produce differentiated learning experiences for individuals who fall outside the ideations of the dominant discourses. Below, the concept of social absence is further explained to help with better conceptualizing online selves.

\section{At the Intersection of Presence and Absence: Sociocultural Production of Online Selves}

In online spaces, one's social presence or social absence operates as a proxy for subjectivities since individuals use their presence and absence in conveying who they are to other people. That is, individuals assess the context in which they enact their social presence and consider the conditions by which others will make sense of their presence [21]. Then, individuals enact their social presence and social absence in particular ways in order to be accepted or legitimised. The process of writing oneself into an online being and creating a social presence-and consequently social absence-can be linked with the idea of impression management [22]: People have relative control in choosing what information to put online in order to look better while eliminate the unwanted consequences of being identified with subaltern categories of identification. Online selves, therefore, can be thought of as the dynamic process by which individuals from certain cultural groups hide their differences since the difference is the primary point of othering, constituting a fixated form of representation for both the dominant and the subaltern [23]. Social absence, in this regard, can be accepted as the degree to which individuals hide their differences in online spaces through the process of self-monitoring. Consequently, one's social presence or absence is contingent on the dynamics of what constitutes the subaltern or how the Others are defined.

The idea of social absence suggests that individuals may hide behind their relative anonymity to overcome exclusion based on their socio-cultural identifications [24]. Indeed, one study reports that when individuals have lower levels of social presence (this should also be read as when individuals have higher levels of social absence), they perceive that they have more equal opportunities to participate [25]. Unfortunately, that study does not further explain the negative correlation between social presence and learning, nor does it conceptualize the results as a matter of social justice. Nevertheless, it can be concluded that hiding behind relative anonymity does not necessarily mean that individuals are exempt from identifications. Rather, it may mean that individuals pretend to be someone else in order to be identified with dominant discourses. For example, one study indicates that, though the participants did not generally perceive gender as an issue in their everyday interactions, a female 
student articulated that gender differences did not completely disappear [16]. The female student in that study characterised her experience as "ideal blend of personalities" as she was performing "male behaviours" and being more "macho" since she was situated in a male-dominated environment and enacting a stereotypical masculinity. Thus, her social absence (the extent that she filtered-out her femininity but performed masculinity) can exemplify how individuals try to be identified with dominant identifications in order to avoid exclusion.

Another example can be found in a study that explores online education from post-colonial perspectives. A work described in [26] analyses the sociocultural fabric in online spaces with respect to the concept of whiteness. In this ethnographic study, for those who were identified as white, identification seemed to have no significant effect, if any, on their social absence. For them, social absence was defined in terms of personal traits or hobbies. For those who were identified as non-white, however, social absence had a different meaning. Their social absence was part of their cultural background: race, ethnicity, or nationality. To be more specific, one participant posited that she did not believe she represented herself truly because her ethnicity was absent. She argued that her online self was only half of herself. Thus, for those who were identified as non-white, social absence was the means by which they were identified as different from whites. Being caught in white interpretative lenses, those who are identified as non-white experienced their online selves from two oppositional subject positions. Another participant in that same study postulated that she could not share much with her peers because she hid her race, faith and country of origin. Accordingly, those who were identified as non-white had to "play by the rule" and be "very very very careful" (p.99) with negotiating their social presence and social absence. Consequently, in that study, the tension between identity and anonymity was a delicate balance that those who are identified as non-white have to figure out in order to claim their right to be included in their online learning community.

It is important to note that while the aforementioned studies discuss gender and race/ethnicity in detail, the analytical capacity of social absence is not limited with those two categories of identification. Just to reiterate, social absence is not about a certain identification, rather, it is about identifications that are filtered out. In this sense, social absence can be employed in any networked learning research that is concerned with social justice.

As the examples above illustrate, the dynamic interplay between social presence and absence can provide the means to explore the effects of discourses in online spaces. In particular, the degree of filtered-out qualities can explain the otherwise hidden effects of cultural hegemony on the construction of self in online learning environments [27]. In order to better explain and exemplify how discourses affect the individuals' subjectivities, below, the author scrutinizes the context in and cultural practices by which social presence and absence are created: the community.

\section{Online Communities: Where We Start is Where We End}

Educational researchers have long studied the online context and culture through the concept of community. Before the relationship between the self and community is discussed, however, it is important to clarify how the authors' arguments are situated in the literature of networked learning. Mainly, there are two opposing perspectives $[19,28]$. On one end of the spectrum, there are researchers who regard online communities as a culture in itself, one which is free from any societal limits or cultural constrains. According to this perspective, people have greater level of freedom and autonomy for creating, enacting and negotiating their online selves [29]. On the other end of the spectrum, there are those who view online communities as a cultural artefact, one which is an extension of the existing societal hierarchies and cultural norms. In this perspective, people have very little choices to exercise their autonomy as the societal discourses dictate who can think, say and enact [30]. This article appreciates both perspectives despite the apparent oppositions in order to recognise the complex interplay between the constrains of discourses and individual autonomy. In fact, it is through this dynamic relationship between the two that social absence finds its analytical power: Discourses 
continue to define who can be what in online spaces, but people use their autonomy to negotiate these constraints in order to navigate their way through their communities.

While defined as a group of individuals who collaboratively engage in a purposeful dialogue to construct personal meaning and confirm mutual understandings [18], the concept of community has been employed to explain what the online learning context is [31], how it relates to online culture [32], how it mediates pedagogy [33] and how it plays a role in learning online [34]. The central idea of the concept of community is that culture mediates practices and pedagogies and that a community is built around the mutuality of meanings, purposes and practices. This mutuality is the foundation for networked learning practices because without the community, learning will be a matter of individual phenomenon [35].

However, mutual meanings may not always support a coherent sense of community and may have consequences for particular individuals or groups as being a member of a community requires individuals to accept (or seem to accept) its core values and norms in order to preserve the integrity of the community [35]. By accepting or rejecting their communities' mutual meanings, individuals can be included into or excluded from certain communities. Thus, in order to be included as a member of a community and be legitimized in their participation, individuals may feel pressured to accept such mutual meanings.

Mutuality of meanings, therefore, is closely related to how individuals make sense of themselves and others, in other words, related to their subjectivities. Indeed, when a community is conceptualized as a zero-institution, it is the membership to such an institution that enables all members to experience themselves as such [36] (p. 1558):

Is then, this zero-institution not ideology as its purest, i.e., the direct embodiment of the ideological function of providing a neutral all encompassing space in which social antagonism is obliterated, in which all members of society can recognize themselves? And is the struggle for hegemony not precisely the struggle for how will this zero-institution be overdetermined, colored by some particular signification?

It is through this battle for hegemony that the online spaces can create conditions for inequitable learning situations: "consensus or group cohesion plays a large role in community life, [and] it is fairly common for members to silence, modify, or limit the fullness of dissenting voices in favour of the dominant opinion ... " [37] (p. 30). The manner in which mutual meanings are defined and negotiated, therefore, impinge on how individuals perceive themselves and thus impact how they construct their social presence and absence. In other words, meanings, subjectivities and the process of identification are interconnected and one's degree of social presence and social absence can reveal how cultural hegemony can reproduce inequitable learning conditions in networked learning activities.

\section{Conclusion}

Online spaces are not exempt from social disputes and struggles. Questions concerning whose values, perspectives and beliefs are legitimised suggest that networked learning spaces can reproduce inequitable learning situations, compelling individuals to filter-out their particular subjectivities in order to be identified with dominant discourses. Precisely because the rhetoric of open/flexible learning disregards such discourses, this article argues that questions concerning social justice do not end with providing access to online spaces. Therefore, researchers interested in networked learning should disregard the claims that online education provides equal opportunities to participate or that online spaces provide a flat hierarchy across different cohorts of students just because it affords anytime-anywhere access. Current frameworks, however, fail to encompass the complexity involved with understanding the extent to which online spaces can provide equitable learning opportunities.

This article concurs that learning is simultaneously a personal and cultural process that requires active participation within learning communities [38] and that engagements with other learners or resources are not sufficient enough to constitute networked learning [39]. This perspective entails the 
exploration of how power dynamics impinge on the ways in which online selves are managed. Then, the work ahead is to conceptualise online selves in depth and breadth, in ways that go beyond what is visible. However, the concept of social presence-the only concept that educational researchers study online selves-is not comprehensive enough to capture and reflect online selves as a process of sociocultural production.

In order to address this issue, the concept of social absence was introduced as a theoretical lens to unpack how power dynamics can manifest themselves in the ways in which online selves are continuously negotiated. The concept of social absence can yield rich enough accounts to illustrate how inequities that exist in day-to-day practices of education are reproduced in online spaces. In tandem with social presence, social absence provides the means to produce more rigorous accounts of better understanding social justice in networked learning activities. For example, currently, online tutors, course instructors or program administrators-or even scholars and researchers-often rely on quantitative measurements of being online, such as checking the number of participations across students or ensuring relatively equal distribution of notes/replies among students. However, this Habermessian notion of an ideal speech condition [40] is elusive and inconclusive. Only because numbers may indicate that there is no apparent problem with communication among students, it does not mean that everybody participates in meaningful ways and learns equally. This article showed that the concept of social absence can provide the means for identifying and further exploring otherwise hidden situations wherein discourses inherent in the social fabric operate to marginalise certain individuals or groups. It should be considered whether students can enact themselves as who they are and truly represent their perspectives when they engage in discussions.

In short, social absence can be employed in any networked learning research that is concerned with social justice. It can provide a rich enough analysis to provide thick enough accounts for post-colonial perspectives, feminist studies, or post-humanist approaches, just to name a few critical research domains.

More critical approaches are needed to networked learning if online courses are to be designed that are more attentive to accommodating the differences among cohorts of students. Networked learning researchers have two options here: First, empty claims can be continued to be produced to be recycled on the open-flexible nature of online education, assuming that effective group work and community-building just happen and that individuals come together as an inclusive group where diversity enriches the learning context; or, second, the focus can be on the concrete ways in which social, historical, political and economic discourses can reproduce unequal learning conditions in online spaces. For those who prefer the second option, this article provides a theoretical framework for more rigorous analysis of online selves and their impact on learning experiences.

Funding: This research received no external funding.

Conflicts of Interest: The author declares no conflict of interest.

\section{References}

1. Harasim, L. Shift happens: Online education as a new paradigm in learning. Internet High. Educ. 2000, 3, 41-61. [CrossRef]

2. Hiltz, S.R.; Turoff, M. Education Goes Digital: The Evolution of Online Learning and the Revolution in Higher Education. Commun. ACM 2005, 48, 59-64. [CrossRef]

3. Mills, J.; Eyre, G.; Harvey, R. What makes provision of e-learning successful? Charles Sturt University's experience in Asia. Educ. Inf. 2005, 23, 43-55. [CrossRef]

4. Bently, J.P.H.; Tinney, M.V. Does culture influence learning? A report on trends in learning styles and preferences across cultures. In Proceedings of the Annual Conference of the Association for Educational Communication \& Technology, Anaheim, CA, USA, 2003.

5. Carvalho, L.; Goodyear, P.; Laat, M.D. Place-Based Spaces for Networked Learning; Routledge: London, UK, 2017. 
6. Goodyear, P. Psychological Foundations for Networked Learning. In Computer Supported Cooperative Work; Springer Science and Business Media LLC: Berlin, Germany, 2002; pp. 49-75.

7. Oztok, M. Cultural Ways of Constructing Knowledge: The Role of Identities in Online Group Discussions. Int. J. Comput. Supported Collab. Learn. 2016, 11, 157-186. [CrossRef]

8. Esmonde, I. Mathematics Learning in Groups: Analyzing Equity in Two Cooperative Activity Structures. J. Learn. Sci. 2009, 18, 247-284. [CrossRef]

9. Gutiérrez, R. (Re)Defining Equity: The Importance of a Critical Perspective. In Improving Access to Mathematics: Diversity and Equity in the Classroom; Nasir, N.I.S., Cobb, P., Eds.; Teachers College Press: New York, NY, USA, 2007; pp. 37-50.

10. Ryberg, T.; Sinclair, C. The Relationships Between Policy, Boundaries and Research in Networked Learning. In Research, Boundaries, and Policy in Networked Learning; Springer Science and Business Media LLC: Berlin, Germany, 2016; pp. 1-20.

11. Holland, D.; Lachicotte, W., Jr.; Skinner, D.; Cain, C. Identity and Agency in Cultural Worlds; Harvard University Press: Cambridge, MA, USA, 1998.

12. Greene, M. Curriculum and Consciousness. Teach. Coll. Rec. 1971, 73, 253-270.

13. Biocca, F.; Harms, C.; Burgoon, J.K. Toward a More Robust Theory and Measure of Social Presence: Review and Suggested Criteria. Presence Teleoperators Virtual Environ. 2003, 12, 456-480. [CrossRef]

14. Öztok, M.; Kehrwald, B.A. Social presence reconsidered: Moving beyond, going back, or killing social presence. Distance Educ. 2017, 38, 259-266. [CrossRef]

15. Bakhtin, M.M.M. Problems of Dostoevsky's Poetics (C. Emerson, Trans.); University of Minnesota Press: Minneapolis, MN, USA, 1984.

16. Ferreday, D.; Hodgson, V.E.; Jones, C. Dialogue, language and identity: Critical issues for networked management learning. Stud. Contin. Educ. 2006, 28, 223-239. [CrossRef]

17. Walther, J.B. Interpersonal Effects in Computer-Mediated Interaction: A Relational Perspective. Commun. Res. 1992, 19, 52-90. [CrossRef]

18. Walther, J.B. Selective self-presentation in computer-mediated communication: Hyperpersonal dimensions of technology, language, and cognition. Comput. Hum. Behav. 2007, 23, 2538-2557. [CrossRef]

19. Hodgson, V. Issues for Democracy and Social Identity in Computer Mediated Communication and Networked Learning. In Computer Supported Cooperative Work; Springer Science and Business Media LLC: Berlin, Germany, 2002; pp. 229-242.

20. Oztok, M.; Brett, C. Social Presence and Online Learning: A Review of Research. J. Distance Educ. $2011,25,1$. Available online: http://www.ijede.ca/index.php/jde/article/view/758/1299 (accessed on 8 May 2019).

21. Riva, G. The Sociocognitive Psychology of Computer-Mediated Communication: The Present and Future of Technology-Based Interactions. CyberPsychology Behav. 2002, 5, 581-598. [CrossRef] [PubMed]

22. Goffman, E. The Presentation of Self in Everyday Life; Anchor: New York, NY, USA, 1959.

23. Spivak, G.C. A Critique of Postcolonial Reason: Toward a History of the Vanishing Present; Harvard University Press: Cambridge, MA, USA, 1999.

24. Rogers, P.; Lea, M. Social presence in distributed group environments: The role of social identity. Behav. Inf. Technol. 2005, 24, 151-158. [CrossRef]

25. Gunawardena, C.N.; Zittle, F.J. Social presence as a predictor of satisfaction within a computer-mediated conferencing environment. Am. J. Distance Educ. 1997, 11, 8-26. [CrossRef]

26. Oztok, M. The Hidden Curriculum of Online Learning: Understanding Social Justice through Critical Pedagogy; Routledge: London, UK, 2019.

27. Yates, S.; Hiles, D. Towards a "Critical Ontology of Ourselves"?: Foucault, Subjectivity and Discourse Analysis. Theory Psychol. 2010, 20, 52-75. [CrossRef]

28. Van Doorn, N. The ties that bind: The networked performance of gender, sexuality and friendship on MySpace. New Media Soc. 2009, 12, 583-602. [CrossRef]

29. Boyd, D. Why Youth Social Network Sites: The Role of Networked Publics in Teenage Social Life. In Youth, Identity, and Digital Media; Buckingham, D., Ed.; MIT Press: Cambridge, MA, USA, 2008; pp. 119-142.

30. Ares, N. Cultural practices in networked classroom learning environments. Int. J. Comput. Collab. Learn. 2008, 3, 301-326. [CrossRef]

31. Hiltz, S.R. The Virtual Classroom: Learning Without Limits Via Computer Networks; Ablex: Norwood, NJ, USA, 1994. 
32. Rheingold, H. Virtual Reality; Summit Books: New York, NY, USA, 1991.

33. Palloff, R.M.; Pratt, K. Lessons from the Cyberspace Classroom: The Realities of Online Teaching; Jossey-Bass: San Francisco, CA, USA, 2001.

34. Garrison, D.; Anderson, T.; Archer, W. Critical Inquiry in a Text-Based Environment: Computer Conferencing in Higher Education. Internet High. Educ. 1999, 2, 87-105. [CrossRef]

35. Hodgson, V.E.; Reynolds, M. Consensus, difference and 'multiple communities' in networked learning. Stud. High. Educ. 2005, 30, 11-24. [CrossRef]

36. Zizek, S. The Matrix, or, the Two Sides of Perversion. In International Handbook of Virtual Learning Environments; Weiss, J., Nolan, J., Hunsinger, J., Trifonas, P.P., Eds.; Springer: Amsterdam, The Netherlands, 2006; pp. 1549-1569.

37. Byrne, D.N. The Future of (the) 'Race': Identity, Discourse, and the Rise of Computer-mediated Public Spheres. In Learning Race and Ethnicity: Youth and Digital Media; Everett, A., Ed.; MIT Press: Cambridge, MA, USA, 2008; pp. 15-38.

38. Cole, M. Cultural Psychology: A once and Future Discipline; Harvard University Press: Cambridge, MA, USA, 1996.

39. Jones, C.; Ryberg, T.; de Laat, M. Networked Learning. In Encyclopedia of Educational Philosophy and Theory; Peters, M.A., Ed.; Springer: Singapore, 2015.

40. Habermas, J. The Theory of Communicative Action, Volume 1: Reason and the Rationalization of Society (T. McCarthy, Trans.); Beacon Press: Boston, MA, USA, 1984.

(C) 2019 by the author. Licensee MDPI, Basel, Switzerland. This article is an open access article distributed under the terms and conditions of the Creative Commons Attribution (CC BY) license (http://creativecommons.org/licenses/by/4.0/). 